\title{
Fabrication of Piezoelectric Polyvinylidene Fluoride (PVDF) Microstructures by Soft Lithography for Tissue Engineering and Cell Biology Applications
}

\author{
Daniel Gallego, Nicholas J. Ferrell, and Derek J. Hansford \\ Biomedical Engineering, The Ohio State University, 270 Bevis Hall, 1080 Carmack Road, \\ Columbus, $\mathrm{OH}, 43210$
}

\begin{abstract}
A method for the fabrication of piezoelectric polyvinylidene fluoride (PVDF) microstructures is described. Embossed and individual features with highly defined geometries at the microscale were obtained using soft lithography-based techniques. Various structure geometries were obtained, including pillars (three different aspect ratios), parallel lines, and criss-crossed lines. SEM characterization revealed uniform patterns with dimensions ranging from $2 \mu \mathrm{m}-15 \mu \mathrm{m}$. Human osteosarcoma (HOS) cell cultures were used to evaluate the cytocompatibility of the microstructures. SEM and fluorescence microscopy showed adequate cell adhesion, proliferation, and strong interaction with tips and corners of the microdiscontinuities. Microfabricated piezoelectric PVDF structures could find applications in the fabrication of mechanically active tissue engineering scaffolds, and the development of dynamic sensors at the cellular and subcellular levels.
\end{abstract}

\section{INTRODUCTION}

Precisely controlled geometries at the micro and nano scale have shown to have great influence on cell behavior. Previous studies found that cells respond strongly to feature dimensions a fraction of their size. For this reason several microfabrication procedures have been adapted from the semiconductor industry to be used in areas like cell biology and tissue engineering among others [1 - 3].

The implementation of certain Microelectromechanical Systems (MEMS) has opened the door for a more precise measurement of biological variables at the microscale, which often allows early diagnostics, and a better understanding of pathophysiological processes affecting organisms. Different groups have pursued research on the fabrication of microsensors to characterize the mechanical interactions of cells with the substrate, which are known to be intimately related with factors such as cell adhesion, cytoskeletal organization, motility, migration patterns, differentiation, and morphogenesis of tissues and organs $[4,5]$.

Micro and nanotechnology have also facilitated the production of tissue engineering scaffolds with controlled morphology and chemistry at the micro and nanoscale, to provide more adequate environments for potential tissue regeneration. Previous research has also shown that for enhanced tissue repair, some cell lines (e.g. osteoblasts and chondrocytes) require external stimuli (e.g. mechanical or electrical), which is why tissue engineering has also been looking into the implementation of active materials, such as conducting polymers and piezoelectric materials, for the fabrication of optimal scaffolds for specific applications [6, 7]. 
This paper describes a method for the production of piezoelectric PVDF structures with controlled geometry at the microscale. Such structures could find applications in the production of tissue engineering scaffolds with the ability to provide mechanical stimulation to cells, the development of cell force sensors, and others.

\section{EXPERIMENTAL DETAILS}

Standard photolithography [8] was used to create masters by patterning a negative SU-8 (MicroChem Corp., USA) photoresist on silicon wafers. Table I describes geometries and dimensions of the patterns. Polydimethylsiloxane (PDMS) negative molds were fabricated from the masters by uniformly mixing PDMS (Silastic T-2, Down Corning, USA) with a curing agent at a 10:1 ratio (wt/wt), pouring the mixture onto the masters, degassing, and curing for 48 hours at room temperature. The masters and the PDMS negative molds were characterized by scanning electron microscopy (SEM).

Table I. Types of geometry (with respective dimensions) patterned by photolithography.

\begin{tabular}{|l|l|}
\hline \multicolumn{1}{|c|}{ Geometry } & \multicolumn{1}{c|}{ Dimensions } \\
\hline Cylindrical pillars & $-5 \mu \mathrm{m}$ diameter, $5 \mu \mathrm{m}$ height \\
& $-5 \mu \mathrm{m}$ diameter, $20 \mu \mathrm{m}$ height (high aspect ratio) \\
\hline Criss-crossed lines & $5 \mu \mathrm{m}$ wide $\mathrm{x} 5 \mu \mathrm{m}$ thick lines spaced by $45 \mu \mathrm{m}$ (between parallel lines) \\
\hline Parallel lines & $5 \mu \mathrm{m}$ wide $\mathrm{x} 3 \mu \mathrm{m}$ thick parallel lines spaced by $45 \mu \mathrm{m}$ \\
\hline
\end{tabular}

Individual and embossed PVDF microfeatures were fabricated from the PDMS molds using soft lithography-based techniques [9], and characterized via SEM. For embossed features a PVDF film was produced by spin coating a 10\% (wt/wt) PVDF (Aldrich, USA) solution on a glass cover slip (Fisher, USA) at $3000 \mathrm{rpm}$ for 1 minute. PVDF was dissolved in N, N dimethylacetamide (Aldrich, USA) and acetone (Mallinckrodt Chemicals, USA) at a 1:4:5 (wt/wt/wt) ratio. The PDMS molds were used to emboss the PVDF into the microfeatures, applying approximately $32 \mathrm{psi}$ at $90^{\circ} \mathrm{C}$ for 5 minutes. For individual features the PVDF solution was spun onto the PDMS molds at $2000 \mathrm{rpm}$ for 1 minute. The PVDF that accumulated on the raised portions of the molds was removed by using a preheated glass slide $\left(\mathrm{T}=200^{\circ} \mathrm{C}\right)$. The PVDF in the recessed regions was stamped out onto glass cover slips by applying about 35 psi at $180^{\circ} \mathrm{C}$ for 10 seconds. In both cases lower spin speeds $(700-1000 \mathrm{rpm})$ were used for the fabrication of high aspect ratio features. Figure 1 shows a schematic of the process used to obtain embossed and individual PVDF microstructures. 
A

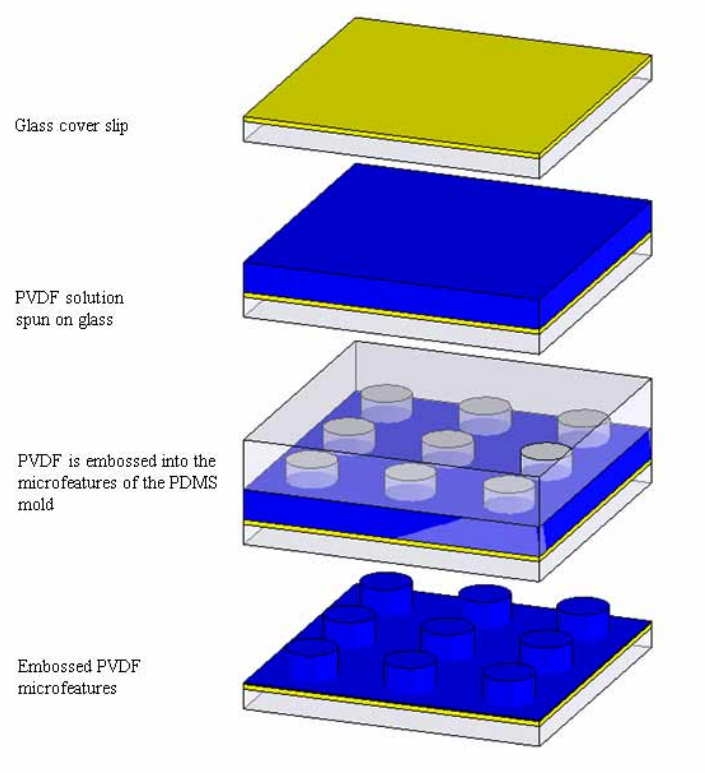

B

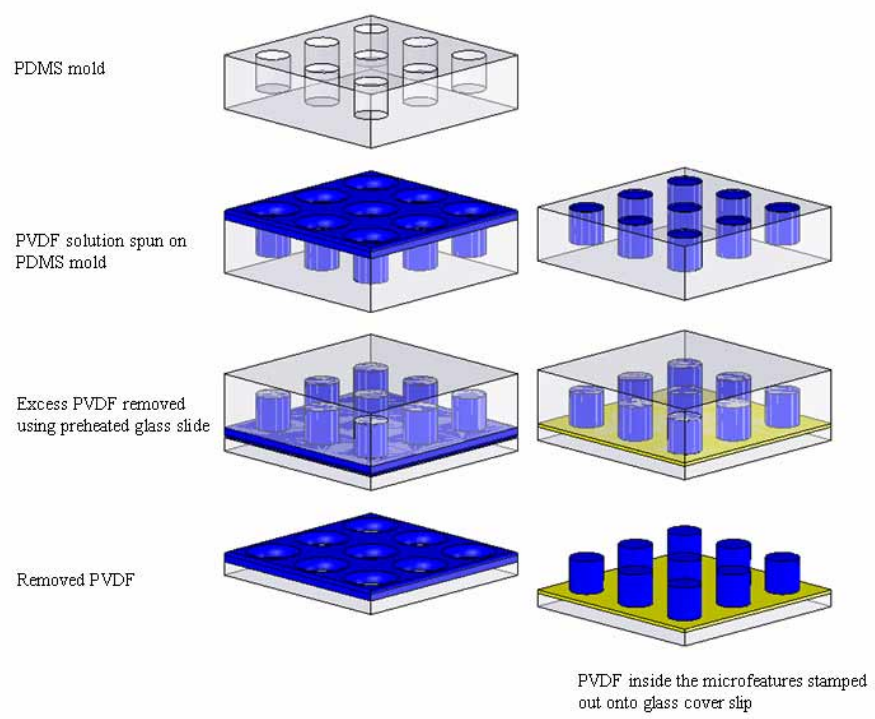

Figure 1. Schematic of the fabrication procedure used for (A) embossed and (B) individual PVDF microfeatures

HOS cell cultures were used to evaluate the cytocompatibility of PVDF microstructures. The cells were seeded on top of previously sterilized (ultraviolet light irradiation for 24 hours) substrates at a density of $10^{5}$ cells $/ \mathrm{cm}^{2}$, and incubated in minimum essential medium (ATCC, USA) supplemented with $10 \%$ fetal bovine serum (ATCC, USA) and $1 \%$ of antibiotics/antimycotics (ATCC, USA) for 24 hours. Flat PVDF substrates and glass slides were used as controls. Cells cultured on glass slides suspended in medium with $20 \%$ ethanol were used as cytotoxic controls. Fluorescence microscopy and SEM were used to qualitatively evaluate cell adhesion, spreading and proliferation. For fluorescence microscopy a postmortem stain of cell nuclei was done with PIRNase (BD Biosciences, USA) at $4^{\circ} \mathrm{C}$ for 10 minutes. For SEM imaging the cells were dehydrated in graded ethanol solutions $(70,80,90$, and $100 \%)$ and hexamethyldisilazane (Ted Pella, USA) according to a procedure described elsewhere [10].

\section{DISCUSSION}

SEM characterization of the masters and PDMS molds (data not shown) revealed uniform patterns with geometries and dimensions comparable to what was described in table I. PVDF microfeatures (embossed and individual) also showed consistency and highly defined topographies at the microscale (see figure 2). The dimensions of the features ranged from $3 \mu \mathrm{m}$ up to $20 \mu \mathrm{m}$ approximately. Variations of the spin speed during solution casting influenced the thickness of the microfeatures. Individual microstructures were successfully stamped onto glass slides. No residual polymer in-between the features was observed (figure $2 \mathrm{~A}, \mathrm{~B}$ ). As expected a thin (thickness $<1 \mu \mathrm{m}$ ) PVDF layer was noticed in-between and below embossed microfeatures (figure2 $\mathrm{C}-\mathrm{F}$ ). 

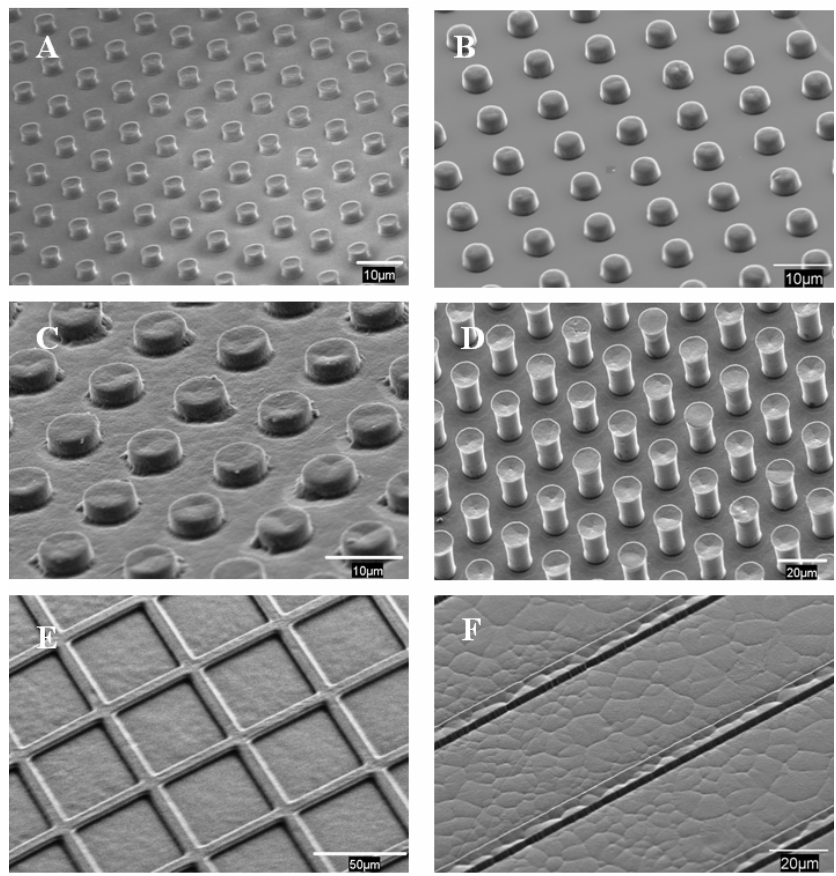

Figure 2. SEM micrographs of (A, B) individual pillars, (C, D) embossed pillars, (E) crisscrossed lines, and $(\mathrm{F})$ parallel lines.

The cytocompatibility of PVDF microstructures was confirmed via 24-hour HOS cell cultures. The cells were able to adhere and proliferate similarly well on all the substrates (micropatterned PVDF, flat PVDF, and glass slides), except on the cytotoxic controls. Figure 3 shows fluorescence microscopy images of cells attached to the substrates (cell nuclei stained red), forming a highly confluent and evenly distributed monolayer.
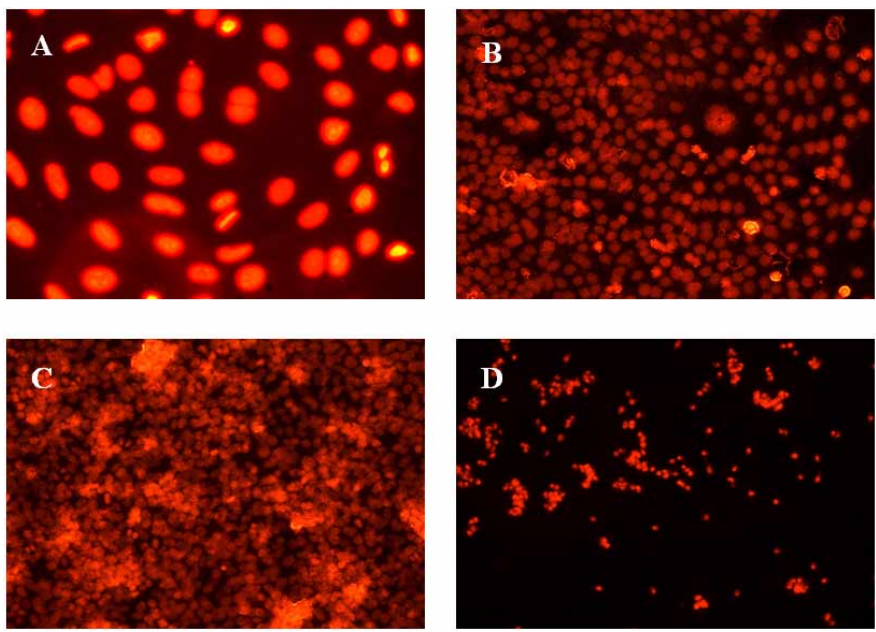

Figure 3. Fluorescence microscopy images of HOS cells (cell nuclei stained red with PIRNase) attached to (A) embossed PVDF micropillars (40X), (B) flat PVDF (20 X), (C) glass slides (20X), (D) cytotoxic controls (10X). 
SEM characterization revealed the cells presented strong interactions with tips and corners of the microfeatures (see figures 4 A, B). This could be due to increased surface energy at those sites, which promoted preferential cell adhesion [11]. Cell morphology was highly influenced by the substrate geometry. Cells grown on micropatterned PVDF (embossed and individual) spread according to the distribution of the microfeatures. Cells grown on flat PVDF and glass slides exhibited random morphologies; however, the cells on flat PVDF tended to be less spread than the cells grown on glass slides (see figures $4 \mathrm{C}, \mathrm{D}$ ). This could be attributed to the fact that PVDF is highly hydrophobic, which could have restricted to some degree cell spreading and adhesion. Previous studies documented enhanced cell adhesion and proliferation on PVDF after modifying the surface chemistry by immobilizing adhesion-promoting peptides $[12,13]$. Modifications on surface topography could also greatly improve cell interactions with the substrate $[11,14]$.
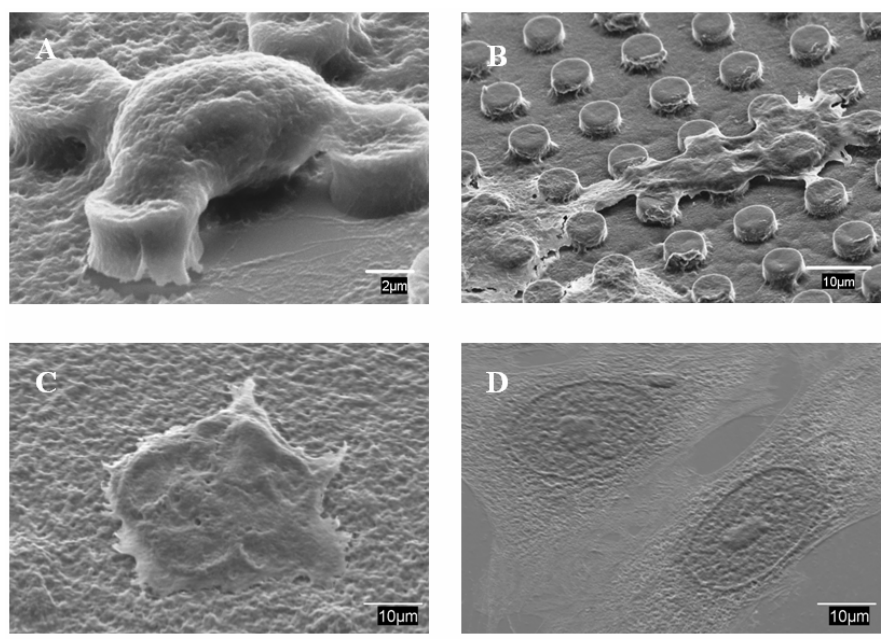

Figure 4. SEM micrographs of HOS cells attached to (A) individual pillars, (B) embossed pillars, (C) flat PVDF, and (D) glass slides.

Preliminary experiments (data not shown) on poling and actuation showed the microfeatures could be effectively poled by applying electric fields of up to $400 \mathrm{MV} / \mathrm{m}$ at $160^{\circ} \mathrm{C}$ for 4 hours, and that electrical stimulation (after poling) between 0 and $5 \mathrm{~V} / \mu \mathrm{m}$ could produce strains around $7 \%$ (as measured by atomic force microscopy).Current research is focused on a more in depth study of the cytocompatibility of PVDF microstructures (by performing quantitative analysis on cell proliferation), and their piezoelectric properties.

\section{CONCLUSIONS}

Individual and embossed piezoelectric PVDF microstructures with highly defined geometries at the microscale were successfully fabricated by using soft lithography-based techniques. Cytocompatibility testing showed adequate cell responses to the material. Cells also exhibited strong interactions with the microfeatures (preferential cell adhesion to tips and corners), which influenced cell spreading and morphology. Preliminary experiments on poling 
and actuation revealed a marked piezoelectric response of the microstructures. Piezoelectric PVDF microstructures could find applications in the production of mechanically active tissue engineering scaffolds, and the development of dynamic cell and tissue sensors at the microscale.

\section{ACKNOWLEDGMENTS}

The authors would like to thank Natalia Higuita (The Ohio State University, Grupo de Investigacion en Ingenieria Biomedica EIA-CES) for assistance with cell culture experiments, and The Nanotech West Laboratory. This work was supported by AFOSR MURI contract \# F49620-03-1-0421 (J. Fuller and H.C. Delong, P.M.s).

\section{REFERENCES}

1. M.J. Dalby., M.O. Riehle, H. Johstone, S. Affrossman, A.S. Curtis, Cell. Biol. Int. 28, 229 (2004).

2. M.J. Dalby, M.O. Riehle, H. Johstone, S. Affrossman, A.S. Curtis, Biomaterials 23, 2945 (2002).

3. J.O. Gallagher, K.F. McGhee, C.D.W Wilkinson, M.O. Riehle, IEEE Trans. Nanobiosci 1, 24 (2002).

4. J. Voldman, M.L. Gray, M.A. Schmidt, Annu Rev Biomed Eng 01, 401 (1999).

5. C.G. Galbraith, M.O. Sheetz, Curr. Opin. Cell. Biol. 10, 566 (1998)

6. S.N. Bhatia, C.S. Chen, Biomedical Microdevices 2, 131 (1999).

7. J.I. Aguirre, L.I. Plotkin, S.A. Stewart, R.S. Weinstein, A.M. Parfitt, S.C. Manolagas, T. Bellido, J Bone Miner Res 21, 605 (2006).

8. M. Madou, Fundumentals of Microfabrication, (CRC Press, Boca Raton, 1997) p 2.

9. Y. Xia, G.M. Whitesides, Annu. Rev. Mater. Sci. 28, 153 (1998).

10. F. Braet, R. De Zanger, E. Wisse, Journal of Microscopy 186, 84 (1997).

11. E.T. den Braber, J.E. de Ruijter, L.A. Ginsel, A.F. von Recum, J.A. Jansen, J. Biomed. Mater. Res. 29, 511 (1995).

12. H.F. Lu, W.S. Lim, J. Wang, Z.Q. Tang, P.C. Zhang, K.W. Leong, S.M. Chia, H. Yu, H.Q. Mao, Biomaterials 24, 4893 (2003).

13. D. Klee, Z. Ademovic, A. Bosserhoff, H. Hoecker, G. Maziolis, H.J. Erli, Biomaterials 24, 3663 (2003).

14. M. J. Dalby, D. McCloy, M. Robertson, H. Agheli, D. Sutherland, S. Affrossman, R.O.C. Oreffo, Biomaterials 27, 2980 (2006). 